\title{
Anastrozole-Induced Dermatitis: Report of a Woman with an Anastrozole-Associated Dermatosis and a Review of Aromatase Inhibitor-Related Cutaneous Adverse Events
}

Yoo Jung Kim · Philip R. Cohen

Received: December 3, 2019 / Published online: January 21, 2020

(C) The Author(s) 2020

\begin{abstract}
Anastrozole is an aromatase inhibitor. Anastrozole competitively inhibits the aromatase enzyme, which synthesizes estrogen. It is used for estrogen receptor-positive breast cancers. A woman with breast cancer and anastrozole-induced dermatitis is described; the cutaneous side effects associated with aromatase inhibitors are also reviewed. Skin-related adverse events associated with aromatase inhibitor use are uncommon and may be delayed in appearance; the time of onset ranges from less than 5 days to 6 months (median 2 months). They present as either vasculitis, erythema nodosum, subacute cutaneous lupus erythematosus, or other dermatoses. Some patients demonstrate cutaneous lesions at either the original site of the breast malignancy or in areas that were previously
\end{abstract}

Enhanced Digital Features To view enhanced digital features for this article go to https://doi.org/10.6084/ m9.figshare.11494050.

Y. J. Kim

Stanford University School of Medicine, Stanford, CA, USA

P. R. Cohen $(\varangle)$

San Diego Family Dermatology, National City, CA, USA

e-mail: mitehead@gmail.com

P. R. Cohen

Touro University California College of Osteopathic

Medicine, Vallejo, CA, USA treated with surgery or radiotherapy. The skin reactions are usually treated with discontinuation of the aromatase inhibitor; topical corticosteroids or oral corticosteroids or both are also used for some patients. Our patient's drug reaction occurred 2 months after starting the anastrozole and improved after a course of oral and topical corticosteroids. She was able to be switched to an alternate aromatase inhibitor without a recurrence of her adverse skin reaction.

Keywords: Adverse; Anastrozole; Arimidex; Aromatase; Breast; Cancer; Effect; Exemestane; Letrozole 


\section{Key Summary Points}

Aromatase inhibitors are used as adjuvant therapy in the management of estrogen receptor-positive breast cancer; there are two main classes of aromatase inhibitors: nonsteroidal (anastrozole and letrozole) and steroidal (exemestane).

In contrast to other drug-induced skin reactions, the onset of aromatase inhibitor-associated cutaneous reactions was delayed for at least a month in $69.2 \%$ (9 of 13 women) after initiating therapy with the medication, and the median onset was 2 months after starting treatment with the aromatase inhibitor.

The morphology of aromatase inhibitorassociated cutaneous reactions predominantly includes vasculitis, erythema nodosum, and subacute cutaneous lupus erythematosus.

Management of aromatase inhibitorassociated cutaneous reactions requires discontinuing the specific aromatase inhibitor.

An aromatase inhibitor from a different drug class may be considered for patients who develop an adverse skin reaction from their initial aromatase inhibitor therapy.

\section{INTRODUCTION}

Anastrozole is an aromatase inhibitor [1]. Anastrozole competitively inhibits the aromatase enzyme, which synthesizes estrogen $[1,2]$. It is used for estrogen receptor-positive breast cancers [1, 2]. Skin-related adverse events associated with anastrozole inhibitor use are uncommon [3-18]. The purpose of this paper is to summarize the cutaneous adverse events associated with aromatase inhibitors. To this end, a woman with breast cancer who developed anastrozole-induced dermatitis is described and cutaneous side effects associated with aromatase inhibitors are reviewed. A review of the relevant literature indicated that there can be a delay in the onset of aromatase inhibitor-induced skin-related adverse events; indeed, the median time to the appearance of dermatologic side effects is 2 months. The most common adverse reactions are vasculitis, erythema nodosum, and subacute cutaneous lupus erythematosus. Treatment of the drug-associated dermatosis requires the discontinuation of the aromatase inhibitor; therapy with topical corticosteroids or oral corticosteroids or both has also been initiated for some patients. Switching to an alternate aromatase inhibitor may also be considered following the resolution of the drug-related dermatosis.

\section{CASE REPORT}

A 67-year-old Filipino woman noted a lump in her left breast; she underwent a screening mammogram in August 2018 which revealed a small mass. In November 2018, a repeat mammogram was performed; the mass had increased to $2 \mathrm{~cm}$. A biopsy established a diagnosis of moderately differentiated, high-grade ductal carcinoma in situ that was estrogen and progesterone receptor positive and HER2/neu negative.

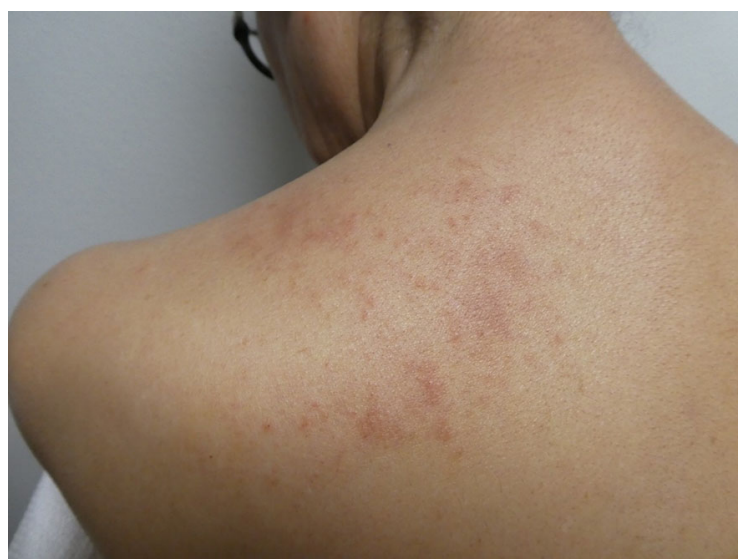

Fig. 1 Anastrozole-induced dermatitis presenting as erythematous patches, papules, and plaques on the upper back of a 68-year-old Filipino woman 


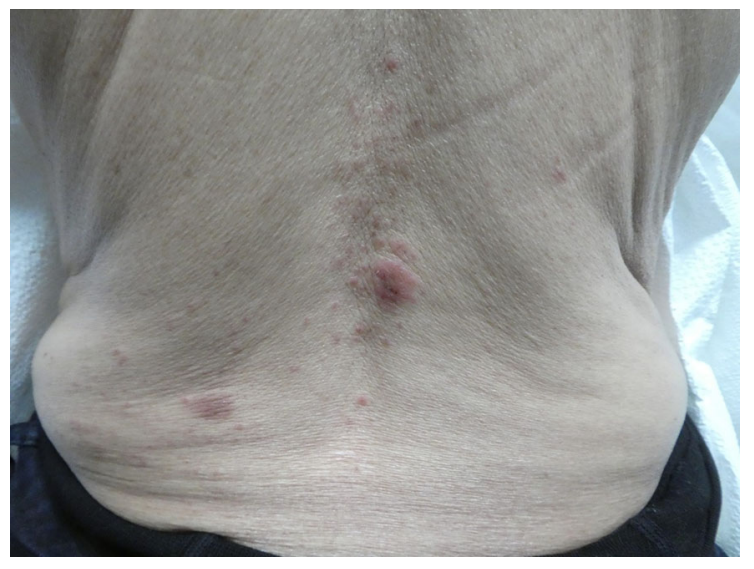

Fig. 2 The lower back of the 68-year-old Filipino woman also developed pruritic red patches, papules, and plaques 2 months after she started anastrozole

She underwent a left breast mastectomy and lymph node dissection on January 8, 2019; a lymph node was positive for her cancer, placing her breast carcinoma at stage IIa. She completed one cycle of docetaxel and cyclophosphamide on February 12, 2019. She was unable to tolerate the chemotherapy and received no further treatment with these drugs.

She was started on anastrozole on March 20, 2019. On May 15, 2019, an itchy rash on her back, neck, and arms was noted.

Cutaneous examination on June 5, 2019 showed a pruritic eruption along with erythematous patches, papules, and plaques on her upper (Fig. 1) and lower (Fig. 2) back in addition to her posterior neck and arms.

Microscopic examination of the 3-mm punch biopsy of her lower back lesion showed a superficial and deep lichenoid and perivascular infiltrate of lymphocytes and numerous eosinophils. These pathologic changes were consistent with a hypersensitivity reaction to a medication. Correlation of the patient's clinical history with the pathologic findings established a diagnosis of a drug reaction to anastrozole.

The anastrozole was discontinued on June 5, 2019 after conferring with her oncologist. She was prescribed oral prednisone $(60 \mathrm{mg}$ daily for 7 days, followed by $40 \mathrm{mg}$ daily for 5 days and then $20 \mathrm{mg}$ daily for 3 days) and topical betamethasone cream $0.05 \%$ twice daily. At her follow-up visit 6 days later, her pruritus had markedly diminished and the dermatitis had improved by $90 \%$. The subsequent follow-up showed complete clearance of the anastrozoleinduced dermatitis.

Her oncologist started her on exemestane, an irreversible steroidal aromatase inactivator, at a daily dosage of $25 \mathrm{mg}$ on July 6,2019 . She had not experienced a recurrence of her dermatitis after 5 months of follow-up. Informed consent was obtained from the participant before they were included in the study. The patient signed a consent providing permission to include clinical photographs in this article.

\section{DISCUSSION}

Aromatase inhibitors are used as adjuvant therapy in the management of estrogen receptor-positive breast cancer. There are two main classes of aromatase inhibitors: nonsteroidal and steroidal. Nonsteroidal aromatase inhibitors include anastrozole and letrozole, which reversibly inhibit the enzyme. Steroidal aromatase inhibitors include testolactone and formestane; these are first- and second-generation aromatase inhibitors, neither of which are currently used. The only third-generation steroidal aromatase inhibitor is exemestane, which irreversibly inactivates aromatase [1, 2].

A review of the relevant literature indicated that erythema nodosum occurred as an adverse skin reaction to aromatase in three patients (Table 1) [3]. Five women receiving either anastrozole, letrozole, or exemestane also developed vasculitis (Table 2) [4-8]. In addition, various other dermatoses have been observed in patients undergoing treatment with aromatase inhibitors (Table 3) [9-18].

Three women developed erythema nodosum after receiving letrozole (Table 1) [3]. The women ranged in age from 47 to 51 years (median 50 years), and presented with either stage II or stage III breast cancer. Each woman received a mastectomy and exhibited their symptoms 2-3 months (median 3 months) after starting letrozole [3].

Erythema nodosum improved after the discontinuation of letrozole. In the case of the 51-year-old patient (case 3 in Table 1), her skin 
Table 1 Erythema nodosum associated with aromatase inhibitor use

\begin{tabular}{|c|c|c|c|}
\hline Case & 1 & 2 & 3 \\
\hline $\mathrm{A} / \mathrm{R} / \mathrm{S}$ & $47 / \mathrm{NS} / \mathrm{W}$ & $50 / \mathrm{NS} / \mathrm{W}$ & $51 / \mathrm{NS} / \mathrm{W}$ \\
\hline Tumor & SII BC & SIII ILC & SII ID BC \\
\hline $\begin{array}{r}\text { Prior } \\
T x\end{array}$ & $\begin{array}{l}\text { Left MRM, } \\
\text { ALND, Dox, } \\
\text { CMF, Tam, } \\
\text { Pac }\end{array}$ & $\begin{array}{l}\text { RM, Dox, Cyc, Thio. CPT, peripheral } \\
\text { blood progenitor support, chest wall } \\
\text { RTx, Tam }\end{array}$ & $\begin{array}{l}\text { MRM, Dox, Cyc, Thio. CPT, peripheral blood } \\
\text { progenitor support, RTx, Tam }\end{array}$ \\
\hline AI & Let & Let & Let \\
\hline OSR & 2 & 3 & 3 \\
\hline SR & $\mathrm{EN}$ & EN & $\mathrm{EN}^{\mathrm{a}}$ \\
\hline Tx & - Let & - Let & - Let, + unspecified steroids \\
\hline CTx & NS & + Ana & NS \\
\hline $\begin{array}{l}\text { Follow- } \\
\text { up }\end{array}$ & $\begin{array}{l}\text { Skin changes } \\
\text { resolved at an } \\
\text { unspecified } \\
\text { time }\end{array}$ & $\begin{array}{l}\text { Ana decreased the number of nodules on } \\
\text { the lower extremities. However, EN still } \\
\text { present } 16 \text { months later }\end{array}$ & $\begin{array}{l}\text { Persistent EN } 6 \text { weeks after discontinuation. } \\
\text { Ana trial one year later caused exacerbation of } \\
\text { EN. Ana was discontinued }\end{array}$ \\
\hline Ref. & Case 2 in [3] & Case 3 in [3] & Case 1 in [3] \\
\hline
\end{tabular}

Santoro et al. [8] listed six cases of erythema nodosum, three of which were triggered by anastrozole and three by letrozole; however, the paper by Jhaveri et al. [3] that Santoro et al. cite for all of these cases includes only three women who developed erythema nodosum associated with letrozole use

$A I$ aromatase inhibitor, $A L N D$ axillary lymph node dissection, $A$ na anastrazole, $A / R / S$ age (years)/race/sex, $B C$ breast cancer, $\mathrm{Ca}$ Caucasian, $C P T$ carboplatin, $C M F$ cyclophosphamide, methotrexate, and 5-fluorouracil, $C T x$ current treatment, Cyc cyclophosphamide, Dox doxorubicin, EN erythema nodosum, ILC invasive lobular carcinoma, Let letrozole, $M R M$ modified radical mastectomy, $N S$ not specified, ID invasive ductal, OSR onset of skin reaction (months), Pac paclitaxel, $S$ stage, $S R$ skin reaction, Ref reference, $R M$ radical mastectomy, $R T x$ radiotherapy, Tam tamoxifen, Thio thiotepa, $W$ woman, + started, - discontinued

a Biopsy showed septal panniculitis with predominant lymphohistiocytic infiltrate consistent with erythema nodosum

reaction improved 6 weeks after discontinuation of letrozole and the administration of systemic corticosteroids [3].

For the 50-year-old patient (case 2 in Table 1), anastrozole was started as an alternate agent after discontinuation of letrozole. However, 1 year following the discontinuation of letrozole, the erythema nodosum continued to persist. The 51-year-old patient (case 3 in Table 1) was started on anastrozole 1 year after discontinuing letrozole, which led to an exacerbation of the patient's erythema nodosum; the anastrozole was therefore discontinued [3].

Vasculitis occurred in five women who were treated with aromatase inhibitors (Table 2)
[4-8]. Their ages ranged from 63 to 80 years (median 72 years). The onset of vasculitis was specified in 3 women; it ranged from 5 to 10 days (median 7 days). One patient (case 2 in Table 2) who had developed vasculitis after taking letrozole was switched to exemestane and noted gradual improvement of her vasculitis [5]. The offending aromatase inhibitor was stopped and no relapses were observed in the remaining women $[6,7]$.

The morphology of the other aromatase inhibitor-induced dermatoses-summarized in Table 3 [9-18]—included subacute cutaneous lupus erythematosus ( 2 women) $[9,16]$, hypersensitivity papular eruption (1 woman-our 
Table 2 Cutaneous vasculitis associated with aromatase inhibitor use

\begin{tabular}{|c|c|c|c|c|c|}
\hline Case & 1 & 2 & 3 & 4 & 5 \\
\hline $\mathrm{A} / \mathrm{R} / \mathrm{S}$ & 63/Bla/W & 69/NS/W & 72/NS/W & $78 / \mathrm{J} / \mathrm{W}$ & $80 / \mathrm{NS} / \mathrm{W}$ \\
\hline Tumor & SIV BC & SIIa BC & LILC & $\mathrm{BC}$ & SIV BC \\
\hline Prior $\mathrm{Tx}$ & Lump, RTx, Tam & $\begin{array}{l}\text { Lump, RTx, } \\
\text { Tam }\end{array}$ & None & Total resection & $\begin{array}{l}\text { Dox, Cyc, 5-FU, } \\
\text { MTX }\end{array}$ \\
\hline AI & Ana to Let $^{a}$ & Let & Let & Ana & Exe \\
\hline OSR & NS & 5 & 10 & $\mathrm{~N} S^{\mathrm{b}}$ & 7 \\
\hline SR & Vasculitis $^{\mathrm{c}}$ & Vasculitis $^{\mathrm{d}}$ & Vasculitis $^{\mathrm{e}}$ & Vasculitis $^{\mathrm{f}}$ & Vasculitis $^{\mathrm{g}}$ \\
\hline $\mathrm{Tx}$ & $\begin{array}{l}\text { - Let, } \\
\text { + colchicine }\end{array}$ & - Let, + Cs & $\begin{array}{l}- \text { Let, }+ \text { Top \& Oral } \\
\text { Cs }\end{array}$ & - Ana & - Exe, + MPred \\
\hline CTx & Tra, Ful & Exe & WLE, RTx, Tam & NS & NS \\
\hline $\begin{array}{l}\text { Follow- } \\
\text { up }\end{array}$ & Rash improved & Rash improved & Rash improved & $\begin{array}{l}\text { Resolved in } \\
2 \text { weeks }\end{array}$ & No relapse \\
\hline Ref. & {$[4]$} & [5] & [6] & [7] & {$[8]$} \\
\hline
\end{tabular}

5-FU 5-fluorouracil, $A I$ aromatase inhibitor, Ana anastrozole, $A / R / S$ age (years)/race/sex, $B C$ breast cancer, Bla Black, $C s$ corticosteroids, CTx current treatment, $C y c$ cyclophosphamide, Dox doxorubicin, Exe exemestane, Ful fulvestrant, $J$ Japanese, Let letrozole, LILC left invasive lobular carcinoma, MPred methylprednisone, MTX methotrexate, NS not specified, $O S R$ onset of skin reaction (days), Ref reference, $R T x$ radiotherapy, $S$ stage, $S R$ skin reaction, Tam tamoxifen, Top topical, Tra trastuzumab, $T x$ treatment, $W$ woman, $W L E$ wide local excision, + started, - discontinued, $\&$ and

a Patient developed arthralgia with initial anastrozole therapy and was switched to letrozole. However, the arthralgia persisted and the patient developed skin lesions after an unspecified time

b Anastrozole was prescribed in January 2003 and the first skin symptoms appeared in April 2003

c A biopsy showed lymphocytes and neutrophils in the vessel walls; these changes were diagnostic of leukocytoclastic vasculitis. Parakeratosis and vacuolar alteration along the dermoepidermal junction with superficial and deep perivascular and interstitial mixed infiltrate-consistent with connective tissue disease-were also present

d Biopsy showed leukocytoclastic vasculitis with neutrophils and lymphocytes infiltrating the dermis

e Biopsy, taken before the start of corticosteroids, showed a leukocytoclastic vasculitis with neutrophils and eosinophils surrounding blood vessels and infiltration of vessel walls with fibrinoid necrosis

${ }^{\mathrm{f}}$ Biopsy showed perivascular infiltration of inflammatory cells

g Biopsy showed superficial dermal edema, fibrinoid necrosis, thickening of the vessel walls, superficial and deep (predominantly perivascular) lymphocytic infiltrate, eosinophils, red cells, and leukocytoclastic features

patient), purpuric papules and plaques (1 woman) [15], erythema multiforme (1 woman) [11], systemic sclerosis (1 woman) [10], and cutaneous nodulosis (1 woman) $[14,19]$. The remaining patients' clinical presentation was designated either a grade 2 (1 woman) [13] or a grade 3 (1 woman) [18] skin reaction. The appearance of the cutaneous adverse event was not described for two of the women [17].

Two of the women experienced aromatase inhibitor-induced dermatoses at the site of previous breast cancer excision or radiotherapy $[11,15]$. A 72-year-old woman who had undergone a left breast mastectomy developed an irregular purpuric plaque with papules at the site of the postoperative scar 6 months after the administration of anastrozole [15]. A 64-yearold woman whose advanced breast cancer had previously been treated with radiotherapy demonstrated a bullous eruption localized to the affected breast after starting an aromatase inhibitor [11]. We postulate that the aromatase 


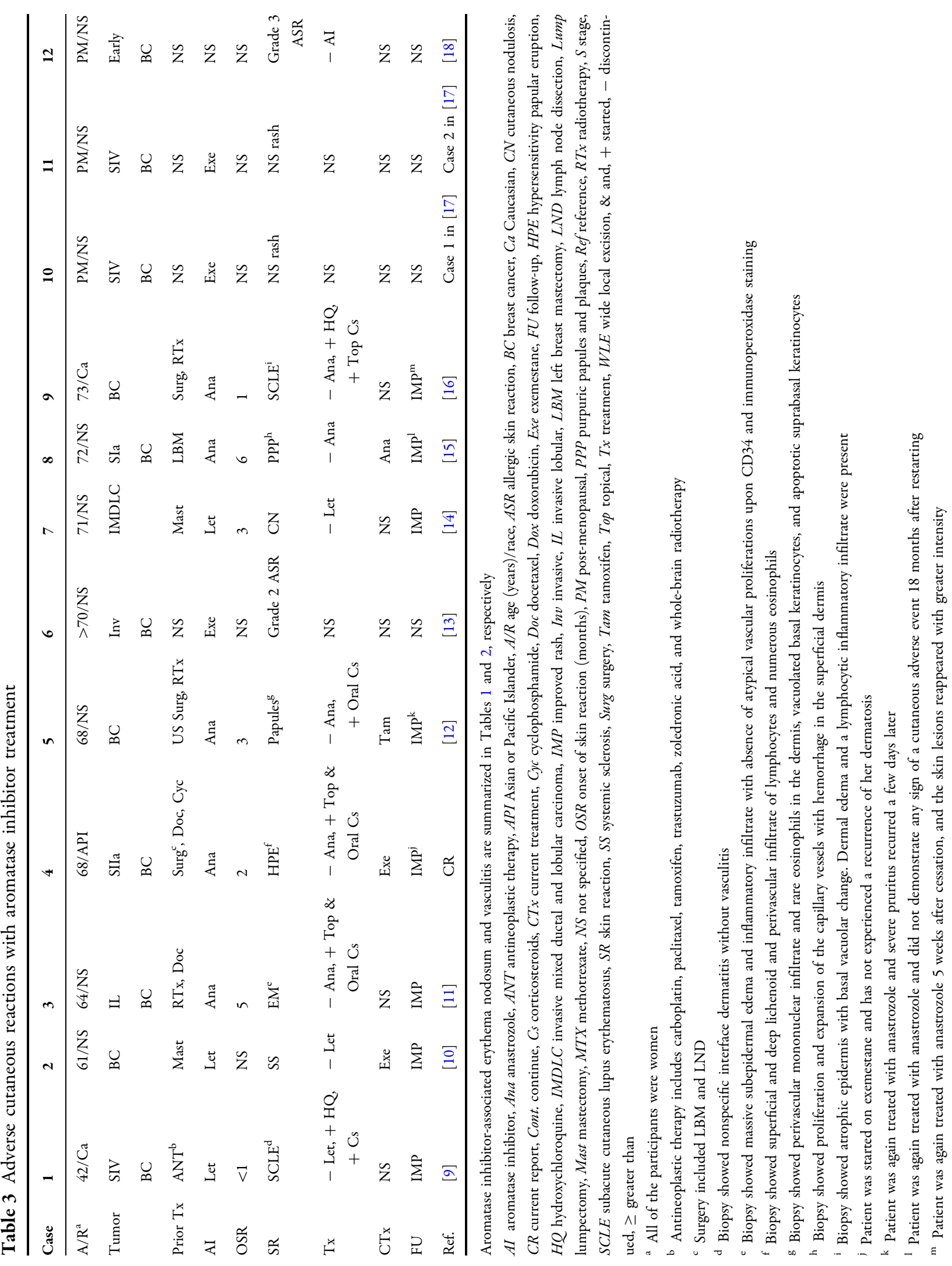


inhibitor-induced skin adverse events in these women occurred in an immunocompromised district-a localized area of immune destabilization (resulting from either the excision or radiotherapy) that enabled the development of the dermatosis in that location [20].

Three of the women (case 3 in Table 1 and cases 5 and 9 in Table 3 ) experienced a recurrence or exacerbation of their initial skin reaction when they were again treated with either the same medication or a different aromatase inhibitor of the same drug class $[3,12,16]$. Another patient (case 2 in Table 1) showed improvement in drug-induced erythema nodosum (although it persisted) when letrozole was switched to anastrozole. Although her skin nodules initially decreased, some were still present after $11 / 3$ years on anastrozole [3]. Surprisingly, a woman who had developed purpuric papules and plaques after being placed on anastrozole did not develop skin lesions after receiving the same drug. Following initial therapy with hydroxyquinoline and topical corticosteroids, she was again treated with anastrozole (1 month after cessation) and did not develop a recurrence of her cutaneous reaction during the subsequent 18 months [15].

Our patient was treated with an alternative aromatase inhibitor of a different drug class, exemestane, after discontinuing anastrozole and did not experience a recurrence of her dermatosis. An aromatase inhibitor from a different drug class may be considered for patients who develop an adverse skin reaction from their initial aromatase inhibitor therapy.

In summary, the patient described in this paper is important not only due to the onset of cutaneous side effects of aromatase inhibitors but also because of her relevance to the potential management of individuals who experience this adverse skin event. Specifically, she exemplifies a case of delayed onset of an aromatase inhibitor-related adverse cutaneous event: her dermatosis initially appeared 2 months after starting the medication. In addition, the patient was able to be treated with a aromatase inhibitor of a different drug class without recurrence of her dermatosis or a different dermatologic adverse event. Hence, when aromatase inhibitor therapy is essential for the management of the patient's cancer but there has been a cutaneous side effect of this therapy, it may be possible to initiate treatment using a different drug class of aromatase inhibitor therapy.

Including our patient, cutaneous adverse events associated with aromatase inhibitor use have been described in 20 women. Their ages ranged from 42 to 80 years old; the median age was 68 years. Patients were receiving either anastrozole (6 women), exemestane (4 women), or letrozole ( 9 women); the specific aromatase inhibitor was not described for one of the patients. The onset of skin reactions following the initiation of aromatase inhibitor therapy was specified in 13 women; the onset of the skin reaction ranged from 5 days to 6 months (median 2 months) after the start of treatment.

\section{CONCLUSIONS}

Aromatase inhibitors are an integral component in the management of breast cancer. Although adverse skin events associated wih aromatase inhibitor use are uncommon, they may occur. In contrast to other drug-induced skin reactions, the onset of aromatase inhibitor-associated cutaneous reactions was delayed for at least a month in $69.2 \%$ of women (9 of 13) after initiating therapy with the medication; indeed, the median onset was 2 months after starting treatment with the aromatase inhibitor. In our patient, the onset of her aromatase inhibitorinduced hypersensitivity papular eruption occurred 2 months after starting anastrozole. Management requires discontinuing the specific aromatase inhibitor; however, our patient was able to be treated with an alternative aromatase inhibitor from a different drug class without a recurrence of her adverse skin reaction.

\section{ACKNOWLEDGMENTS}

We thank the participants of the study. The opinions expressed in the manuscript are those of the authors. 
Funding. No funding was received for the publication of this article. The authors are fully responsible for all content and editorial decisions and received no financial support or other forms of compensation related to the development of this manuscript.

Authorship. All named authors meet the International Committee of Medical Journal Editors (ICMJE) criteria for authorship of this manuscript, take responsibility for the integrity of the work as a whole, and have given final approval of the version to be published.

Disclosures. Yoo Jung Kim and Philip R. Cohen have nothing to disclose with regard to the publication of this article. Philip R. Cohen is a member of the journal's Editorial Board.

Compliance with Ethics Guidelines. Informed consent was obtained from the participant before they were included in the study. The patient signed a consent providing permission to include clinical photographs in this article.

Data Availability. Data sharing is not applicable to this article as no data sets were generated or analyzed during the current study

Open Access. This article is licensed under a Creative Commons Attribution-NonCommercial 4.0 International License, which permits any non-commercial use, sharing, adaptation, distribution and reproduction in any medium or format, as long as you give appropriate credit to the original author(s) and the source, provide a link to the Creative Commons licence, and indicate if changes were made. The images or other third party material in this article are included in the article's Creative Commons licence, unless indicated otherwise in a credit line to the material. If material is not included in the article's Creative Commons licence and your intended use is not permitted by statutory regulation or exceeds the permitted use, you will need to obtain permission directly from the copyright holder. To view a copy of this licence, visit http://creativecommons.org/licenses/by$\mathrm{nc} / 4.0 /$.

\section{REFERENCES}

1. Jameera Begam A, Jubie S, Nanjan MJ. Estrogen receptor agonists/antagonists in breast cancer therapy: a critical review. Bioorg Chem. 2017;71: 257-74

2. Robert NJ, Denduluri N. Patient case lessons: endocrine management of advanced breast cancer. Clin Breast Cancer. 2018;18:192-204.

3. Jhaveri K, Halperin P, Shin SJ, Vahdat L. Erythema nodosum secondary to aromatase inhibitor use in breast cancer patients: case reports and review of the literature. Breast Cancer Res Treat. 2007;106: 315-8.

4. Wong M, Grossman J, Hahn BH, La Cava A. Cutaneous vasculitis in breast cancer treated with chemotherapy. Clin Immunol. 2008;129:3-9.

5. Digklia A, Tzika E, Voutsadakis IA. Cutaneous leukocytoclastic vasculitis associated with letrozole. J Oncol Pharm Pract. 2014;20:146-8.

6. Pathmarajah P, Shah K, Taghipour K, Ramachandra S, Thorat MA, Chaudhry Z, Patkar V, Peters F, Connor T, Spurrell E, Tobias JS, Vaidya JS. Letrozole-induced necrotising leukocytoclastic small vessel vasculitis: first report of a case in the UK. Int J Surg Case Rep. 2015;16:77-80.

7. Shoda H, Inokuma S, Yajima N, Tanaka Y, Setoguchi $K$. Cutaneous vasculitis developed in a patient with breast cancer undergoing aromatase inhibitor treatment. Ann Rheum Dis. 2005;64: 651-2.

8. Santoro S, Santini M, Pepe C, Tognetti E, Cortelazzi C, Ficarelli E, De Panfilis G. Aromatase inhibitorinduced skin adverse reactions: exemestane-related cutaneous vasculitis. J Eur Acad Dermatol Venereol. 2011;25:596-8.

9. Zarkavelis G, Kollas A, Kampletsas E, Vasiliou V, Kaltsonoudis E, Drosos A, Khaled H, Pavlidis N. Aromatase inhibitors induced autoimmune disorders in patients with breast cancer: a review. J Advert Res. 2016;7:719-26.

10. Pokhai G, Buzzola R, Abrudescu A. Letrozole-induced very early systemic sclerosis in a patient with breast cancer: a case report. Arch Rheumatol. 2014;29:126-9.

11. Wollina U, Schönlebe J, Heinig B, Tchernev G, França K, Lotti T. Segmental erythema multiformelike drug eruption by aromatase inhibitor anastrozole-first case report and another example of an immunocompromised district. Open Access Maced J Med Sci. 2018;6:79-81. 
12. Bremec T, Demsar J, Luzar B, Pavlović MD. Druginduced pruritic micropapular eruption: anastrozole, a commonly used aromatase inhibitor. Dermatol Online J. 2009;15(7):14.

13. Mustacchi G, Mansutti M, Sacco C, Barni S, Farris A, Cazzaniga M, Cozzi M, Dellach C. Neo-adjuvant exemestane in elderly patients with breast cancer: a phase II, multicentre, open-label, Italian study. Ann Oncol. 2009;20:655-9.

14. Chao J, Parker BA, Zvaifler NJ. Accelerated cutaneous nodulosis associated with aromatase inhibitor therapy in a patient with rheumatoid arthritis. J Rheumatol. 2009;36:1087-8.

15. Tanaka A, Yamashita C, Hinogami H, Shirai $H$, Yamamura J, Ito R. Localized cutaneous adverse event induced by anastrozole as adjuvant treatment for breast cancer: a case report. Case Rep Dermatol. 2019;11:57-63.

16. Trancart M, Cavailhes A, Balme B, Skowron F. Anastrozole-induced subacute cutaneous lupus erythematosus. Br J Dermatol. 2008;158:628-9.
17. Gennatas C, Michalaki V, Carvounis E, Psychogios J, Poulakaki N, Katsiamis G, Voros D, Kouloulias V, Mouratidou D, Tsavaris N. Third-line hormonal treatment with exemestane in postmenopausal patients with advanced breast cancer progressing on letrozole or anastrozole. A phase II trial conducted by the Hellenic Group of Oncology (HELGO). Tumori. 2006;92:13-7.

18. Moscetti L, Agnese Fabbri M, Sperduti I, Fabrizio N, Frittelli P, Massari A, Pompei L, D’Auria G, Pofi E, Ruggeri EM. Adjuvant aromatase inhibitor therapy in early breast cancer: what factors lead patients to discontinue treatment? Tumori. 2015;101:469-73.

19. Williams FM, Cohen PR, Arnett FC. Accelerated cutaneous nodulosis during methotrexate therapy in a patient with rheumatoid arthritis. J Am Acad Dermatol. 1998;39:359-62.

20. Ruocco V, Brunetti G, Puca RV, Ruocco E. The immunocompromised district: a unifying concept for lymphoedematous, herpes-infected and otherwise damaged sites. J Eur Acad Dermatol Venereol. 2009;23:1364-73. 